\title{
Erratum to: Fuite spontanée de liquide céphalo-rachidien
}

\section{Erratum to: Spontaneous cerebro-spinal fluid leaks}

\author{
C. Petit $\cdot$ N. Thoma $\cdot$ N. Modruz $\cdot$ Y. Auffret \\ (C) SFMU et Springer-Verlag France 2013
}

Erratum to : Ann. Fr. Med. Urgence DOI 10.1007/s13341-013-0372-4

Une erreur est apparue dans la Figure 1 de l'article « Fuite spontanée de liquide céphalo-rachidien », paru dans les Annales françaises de médecine d'urgence volume 3 numéro 6 novembre 2013.

Voici l'image correcte :

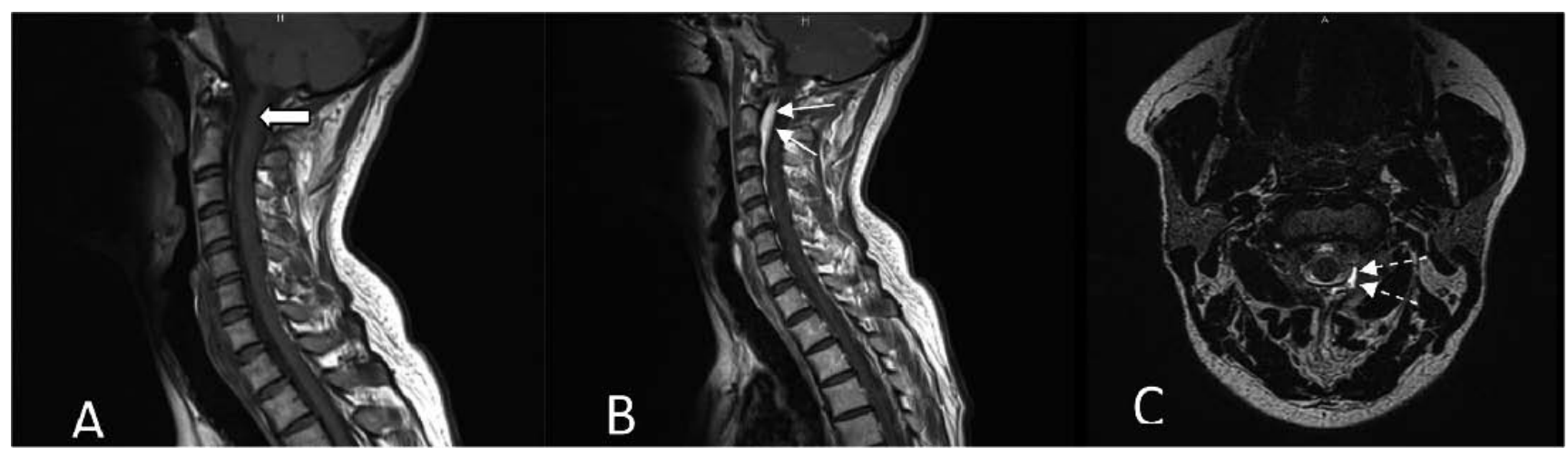

Fig. 1 IRM médullaire. Séquence T1 sans gadolinium, coupe sagittale (A) : absence de signal (flèche blanche large). Séquence T1 avec gadolinium, coupe sagittale $(\mathrm{B})$ : hyperémie du plexus veineux de la première à la quatrième vertèbre cervicale en épidural antérieur (flèches blanches pleines). Séquence 3DCIS, coupe axiale $(\mathrm{C})$ : collection liquidienne périmédullaire (flèches pointillées) 